\title{
Does Intensification Improve the Economic Efficiency of Dairy Farms?
}

\author{
A. Alvarez, ${ }^{*}$ J. del Corral, ${ }^{*}$ D. Solís, $\dagger^{1}$ and J. A. Pérezł \\ *Department of Economics, University of Oviedo, Oviedo 33006, Spain \\ †Division of Marine Affairs and Policy, Rosenstiel School of Marine and Atmospheric Science, University of Miami, Miami, FL 33149 \\ ‡Department of Accounting, University of Oviedo, Oviedo 33006, Spain
}

\begin{abstract}
In recent decades, the dairy sector has shown a global tendency toward intensification. This structural change may have significant effects on farm efficiency and, consequently, on the economic results of the farms. The goal of this study was to offer an empirical analysis of the effect of intensification on dairy farming. To do this, we first classified a sample of dairy farms according to their level of intensification by using a cluster analysis. We then estimated independent stochastic cost frontiers for each group of farms to calculate their levels of efficiency. The methodology used in this study allowed for the presence of different technologies within a sample, which is a methodological issue frequently avoided in the agricultural economics literature. The empirical results showed that intensive farms were closer to their cost frontier than extensive ones, suggesting a positive relationship between intensification and efficiency.
\end{abstract}

Key words: cluster analysis, efficiency, intensification, stochastic cost frontier

\section{INTRODUCTION}

Farm management agents, as well as many researchers, have advocated reducing production costs as a key factor to boost profits on dairy farms. In many cases, the approach implemented to reduce costs has been the adoption of more extensive production systems. Many studies have found that pasture-based systems allow farmers to produce at lower average costs than highinput systems (e.g., Parker et al., 1992; Soder and Rotz, 2001).

However, in recent decades there has been an increasing trend toward adopting more intensive systems. The intensification of production is mainly based on an increase in the number of dairy cows per hectare of land (greater stocking rate), the acquisition of

\footnotetext{
Received February 25, 2008.

Accepted June 5, 2008.

${ }^{1}$ Corresponding author: d.solis@miami.edu
}

genetically improved dairy cattle, and the increase in concentrates in the diet (Caviglia-Harris, 2005). These structural changes may have significant effects on the efficiency of the farms; and therefore, on the economic results of the farms.

Very few studies have analyzed the relationship between intensification and efficiency. For instance, Reinhard et al. (1999) found that, in the Netherlands, intensive dairy farms were more technically and environmentally efficient than extensive farms. Similar outcomes were presented by Simpson and Conrad (1993) in their analysis of beef and dairy cattle production in 7 countries in Central America. Conversely, Ledgard et al. (2004) argued that more intensive production systems increased production and economic efficiency but decreased environmental efficiency among dairy farms in New Zealand. Last, Hallam and Machado (1996) provided mixed evidence in their study of dairy farms in Portugal. These authors reported greater levels of efficiency among intensive farms when the intensification was measured as "feed per cow." In contrast, the opposite outcome was found when "cows per hectare" was used to classify the farms.

Our study contributes to the analysis of the effects of intensification by implementing an alternative approach to the one used in previous research. The abovementioned papers assumed that all producers in the sample used the same technology. However, we argue that the production technology among intensive farms may be different from the technology used by extensive farms. This issue is important because if the farms in the sample use different technologies, then assuming a single technology for all of them may cause serious econometric problems.

In general, the few dairy studies that have addressed the issue of farm heterogeneity (i.e., the presence of different technologies in a sample) have used expert knowledge to divide the sample based on some specific characteristics. For example, Hoch (1962) split his sample of Minnesota dairy farms into 2 groups based on the location of farms. Bravo-Ureta (1986) classified his sample according to herd breed. Tauer (1998) and Katsumata, and Tauer (2005) estimated different cost 
Table 1. Descriptive statistics for 224 Spanish dairy farms over the period 1999 to 2006

\begin{tabular}{lcccc}
\hline Variable & Mean & $\mathrm{CV}^{1}$ & Minimum & Maximun \\
\hline Average total cost (€/L) & 0.31 & 0.17 & 0.17 & 0.55 \\
Milk (L) & 293,492 & 0.65 & 28,708 & $1,301,600$ \\
Cows (n) & 39 & 0.51 & 8 & 153 \\
Labor (FTE ${ }^{2}$ ) & 1.76 & 0.44 & 0.26 & 8.73 \\
Land (ha) & 19 & 0.56 & 3 & 0.34 \\
Feed price (€/kg) & 0.23 & 0.10 & 0.13 & 1,103 \\
Herd price (€) & 144 & 0.44 & 18 & 56,904 \\
Milk per hectare (L/ha) & 16,404 & 0.46 & 2,850 & 8,150 \\
Milk per cow (L/cow) & 7,196 & 0.21 & 2,585 & 5.20 \\
Feed per cow (kg/cow) & 3,419 & 0.29 & 918 & \\
Cows per hectare (n/ha) & 2.24 & 0.36 & 0.45 & \\
\hline${ }^{1}$ CV = coefficient of variation. & & & &
\end{tabular}

functions for farms using alternative milking systems. Newman and Matthews (2006) estimated independent stochastic distance functions for specialized and nonspecialized dairy farms. It is important to indicate that none of these papers focused on the impact of intensification on farm efficiency. In our study, we implemented a statistical method to split our sample. Specifically, we used a cluster algorithm to classify our sample of dairy farms according to their level of intensification.

The data used in the empirical analysis consisted of a sample of 224 dairy farms that were enrolled in a record-keeping program over an 8-yr period from 1999 to 2006 (i.e., 1,792 observations). The farms are located in Asturias, a northern region in Spain where dairy farming is the main agricultural activity. The climate in northern Spain is Atlantic, with summers that are generally humid and warm, and winters that are fairly mild. Annual rainfall is above $900 \mathrm{~mm}$ and temperatures average approximately $13^{\circ} \mathrm{C}$. These climatic conditions allow for grazing all year round, and for this reason, pasture-based systems have been traditional in northern Spain.

Since the incorporation of Spain into the European Union in 1986 and the adoption of the milk quota regimen, there has been a large reduction in the number of dairy farms in the area under study, allowing existing farmers to buy quota to increase size. However, land is not so readily available because exiting farmers are allowed to use the land for other purposes (in many cases, for beef cows). For this reason, when a dairy farmer acquires more quota, in most cases there will be no or very little land available for purchasing or renting, forcing many farmers to switch to a more intensive system (i.e., greater stocking rate). The dairy farms in the sample are highly specialized, with more than $90 \%$ of the output coming from dairy sales. More information about the area under study and the dairy sector in Asturias can be found in Pérez and Machado (2001).
Consequently, the primary goal of this study was to analyze the effect of dairy farm intensification on the average cost of production. To reach our goal, we first classified our sample of dairy farms according to their level of intensification by using a cluster analysis. We then estimated a cost frontier for each group of farms and calculated their level of cost efficiency. The results of the empirical analysis showed that intensive farms produced at a lower average cost, and they seemed to be managed more efficiently than farms under more extensive systems. These results provide valuable information that can be used by farm managers to improve cost efficiency.

\section{MATERIALS AND METHODS}

\section{Cost Frontiers and Cluster Analysis}

A cost frontier represents the minimum expenditure required to produce any output, given input prices (Kumbhakar and Lovell, 2000, p. 33). Therefore, a cost frontier envelops the data in such a way that all farms must lie on the frontier or above it. Aigner et al. (1977) developed a framework known as stochastic frontier analysis to estimate frontier functions. This method assumes that the error structure is formed by 2 components: an inefficiency term and measurement error. By forcing the inefficiency component to be nonnegative, it is possible to bound the data from below, which is the case of a theoretical cost frontier. In this framework, a stochastic cost frontier (SCF) is specified as:

$$
C=C(w, y, t) \cdot \exp (\varepsilon) ; \varepsilon=v+u ; u \geq 0,
$$

where $C$ is the observed cost, which is a function of input prices $(w)$, output level $(y)$, and the state of the technology $(t)$; and $\varepsilon$ is a composed error term. The 
components of $\varepsilon$ are $v$, which is a random variable reflecting statistical noise, and $u$, which is a nonnegative term that captures farm inefficiency. When $u=0$, the farm is producing on the cost frontier (i.e., at minimum cost), whereas a positive $u$ indicates that the farm cost is above minimum cost.

The SCF depicted in equation [1] allowed us to measure an index for cost efficiency $(C E)$, which is defined as the ratio of the minimum feasible cost $\left(C^{*}\right)$ and observed cost $(C)$ :

$$
C E=\frac{C^{*}}{C}=\frac{C(y, w, t) \cdot \exp (v)}{C(y, w, t) \cdot \exp (u+v)}=\exp (-u) .
$$

Because $C^{*}$ must always be lower than or equal to $C$, the $C E$ index is bounded between 0 and 1 , and achieves its upper bound when a dairy farm is producing its output level at minimum cost (i.e., $C=C^{*}$ ), given the input prices and the technology.

In this study, we used a cluster analysis to classify our sample of dairy farms according to their level of intensification. Cluster analysis is a multivariate statistical procedure that reorganizes a data set into relatively homogeneous groups or clusters. These clusters are generated based on the mathematical relationship of the data. This method sorts the data so that the degree of association is strong between members of the same cluster and weak between members of different clusters (Aldenderfer and Blashfield, 1984; Everitt et al., 2001). Specifically, in this study we used a k-means cluster algorithm, in which the number of groups must be decided by the researcher. To present a clearer analysis of the impact of intensification on production cost and farm efficiency, we selected 2 (i.e., intensive and extensive farms) as the number of clusters. To assign each specific observation (dairy farms, in our case) to a cluster, this methodology uses a measure of similarity between the different units to calculate how far apart they are from each other. To do this, we used the Euclidean distance after standardizing the variables. By implementing this procedure, we were able to estimate separate cost frontiers for farms with different levels of intensification and to calculate the efficiency level of each group.

To test whether the difference between the average efficiency of the 2 groups was statistically significant, we used a $t$-test, for which the $t$-statistic was calculated as

$$
t \text {-statistic }=\frac{\bar{x}_{i}-\bar{x}_{e}}{\sqrt{\frac{\left(n_{i}-1\right) \cdot S_{i}^{2}+\left(n_{e}-1\right) \cdot S_{e}^{2}}{n_{i}+n_{e}-2}} \cdot \sqrt{\frac{1}{n_{i}}+\frac{1}{n_{e}}}},
$$

where $i$ and $e$ stand for the intensive and extensive groups, respectively, $\bar{x}$ is the efficiency mean, $S^{2}$ is the variance, and $n$ is the sample size.

\section{Data}

Table 1 provides a descriptive summary of the main variables used in this study. The total cost included the following items: cost of purchased feeds (concentrates, forages, etc.); forage production costs (seeds, treatments, machinery, etc.); herd expenses (milking, veterinarian, etc.); other expenses (transportation, farm materials, etc.); and fixed costs (social security, opportunity cost of land, opportunity cost of family labor, and amortization of buildings and machinery). The average total cost was calculated by dividing the total cost by milk production. All the monetary values are expressed in 2006 euros (€).

As indicated, to classify our sample of dairy farms according to their level of intensification, we implemented a k-means cluster analysis. Milk per cow, milk per hectare, feed per cow, and cows per hectare were used as separation variables. It is important to note that these variables were measured in ratios to avoid grouping farms based on size. The cluster analysis identified 2 distinctive groups, which we labeled extensive and intensive dairy farms. The clustering process was performed in such a way that the classification of each farm could change over time. Consequently, the 2 groups of farms contained a different number of farms in each year. Table 2 shows the evolution of the rela-

Table 2. Farm classification according to the level of intensification

\begin{tabular}{lrrrrrrrrr}
\hline & \multicolumn{8}{c}{ Year } & \\
\cline { 2 - 9 } Group & 1999 & 2000 & 2001 & 2002 & 2003 & 2004 & 2005 & 2006 & Total \\
\hline Extensive & 193 & 183 & 170 & 148 & 147 & 140 & 133 & 131 & 1,245 \\
Intensive & 31 & 41 & 54 & 76 & 77 & 84 & 91 & 93 & 547 \\
\hline
\end{tabular}


Table 3. Group characteristics (averages of 8 yr, 1999 to 2006)

\begin{tabular}{lcc}
\hline Characteristic & Extensive & Intensive \\
\hline Average total cost (€/L) & 0.31 & 0.29 \\
Milk (L) & 228,137 & 442,240 \\
Cows (n) & 33 & 52 \\
Purchased feed (kg) & 107,420 & 214,385 \\
Labor (FTE ${ }^{1}$ ) & 1.60 & 2.14 \\
Land (ha) & 19 & 18 \\
Feed price (€/kg) & 0.23 & 0.23 \\
Herd price (€) & 132 & 172 \\
Milk per hectare (L/ha) & 12,336 & 25,664 \\
Milk per cow (L/cow) & 6,671 & 8,390 \\
Feed per cow (kg/cow) & 3,140 & 4,056 \\
Cows per hectare (n/ha) & 1.87 & 3.08 \\
Observations (n) & 1,245 & 547 \\
\hline
\end{tabular}

${ }^{1} \mathrm{FTE}$ = full-time equivalent workers.

tive composition of the groups over the sample period. The number of farms classified as intensive increased over the years, whereas the opposite was true for the extensive farms.

Table 3 presents the averages for the 2 groups of farms obtained in the cluster analysis. As expected, farms in the intensive production system produced more milk, owned more productive cows, consumed more feedstuffs, displayed a greater stocking rate, and, as a consequence, produced more milk per hectare than their counterparts. Additionally, the average total cost (i.e., cost per liter of milk) was lower among the intensive farms.

\section{Empirical Model}

The empirical analysis was based on the estimation of independent SCF for intensive and extensive dairy farms classified by using a cluster analysis. To

Table 4. Cost function frontier estimates

\begin{tabular}{lcc}
\hline Item & Extensive & Intensive \\
\hline Constant & $-1.513^{* * *}$ & $-1.481^{* * *}$ \\
Milk & $-0.136^{* * *}$ & $-0.041^{* *}$ \\
Feed price & $0.237^{* * *}$ & $0.194^{* * *}$ \\
Herd price & $0.057^{* * *}$ & $0.092^{* * *}$ \\
(Milk) $^{2}$ & $0.090^{* * *}$ & $0.094^{*}$ \\
(Feed price) $^{2}$ & $-0.615^{*}$ & 0.461 \\
(Herd price) $^{2}$ & $0.064^{* *}$ & $0.111^{* *}$ \\
Milk $\times$ feed price & $-0.229^{* * *}$ & -0.105 \\
Milk $\times$ herd price & $0.036^{*}$ & -0.014 \\
Feed price $\times$ herd price & $-0.209^{* *}$ & 0.116 \\
Time trend & $-0.015^{* * *}$ & $-0.015^{* * *}$ \\
$D 2003$ & $0.051^{* * *}$ & $0.020^{*}$ \\
$\mu$ & $0.369^{* *}$ & 0.271 \\
$\mu$ & 0.011 & 0.006 \\
$\sigma_{u}^{2}$ & 0.012 & 0.009 \\
$\sigma_{v}^{2}$ & 816 & 448 \\
Log likelihood & & \\
\hline
\end{tabular}

${ }^{*} P<0.10 ;{ }^{* *} P<0.05 ;{ }^{* * *} P<0.01$. estimate these functions, we used the translog functional form (Christensen et al., 1973). The dependent variable was the average total cost (ATC), and the independent variables included the production of milk $(y)$, the price of feedstuffs $\left(w_{1}\right)$, and a herd price $\left(w_{2}\right)$. A linear time trend ( $T$ ) was introduced to account for technical change. In addition, a dummy variable for the year 2003 (D2003) was included to account for a severe drought that affected the production of grass and other agricultural products. Thus, the equation to estimate $A T C$ can be expressed as:

$$
\begin{gathered}
\ln A T C_{i t}=\left.\beta_{0}\right|_{j}+\left.\beta_{y}\right|_{j} \ln y_{i t}+\left.\sum_{h=1}^{2} \beta_{w h}\right|_{j} \ln w_{h i t} \\
+\left.\frac{1}{2} \beta_{y y}\right|_{j} \ln y_{i t}^{2}+\left.\frac{1}{2} \sum_{h=1}^{2} \beta_{w h w h}\right|_{j} \ln w_{h i t}^{2}+\left.\sum_{h=1}^{2} \beta_{w h y}\right|_{j} \ln w_{h i t} \ln y_{i t} \\
+\left.\delta_{t}\right|_{j} T+\left.\delta_{D}\right|_{j} D 2003+\left.v_{i t}\right|_{j}+\left.u_{i}\right|_{j},
\end{gathered}
$$

where $v$ is a symmetric error term assumed to follow a normal distribution and $u$ is a time invariant nonnegative error component assumed to follow a truncated normal distribution. The subscript $i$ denotes farm, $t$ indicates time, and $j$ represents the different groups. The vertical bar indicates that the estimation yields parameter estimates for each of the groups. Stata 9.0 was used in all the estimations.

\section{RESULTS AND DISCUSSION}

Table 4 presents the estimated cost frontiers for the extensive and intensive groups of farms. Following common practice, all the explanatory variables in the cost frontiers were normalized by their geometric means so that the first-order coefficients could be interpreted as cost elasticities evaluated at their respective group geometric means. The estimated models presented parameters with a high level of statistical significance. Furthermore, the 2 estimated models displayed parameters with considerable differences, confirming the presence of different technologies between the intensive and extensive farms.

The time trend variable in both estimated models presented a negative and significant value, suggesting the existence of technical change in the sample. Furthermore, the parameter for D2003 was, as expected, positive and statistically significant in both cases. This last result indicates that the adverse climatic condition of 2003 (severe drought) increased the farms' average total cost.

The empirical results also showed that the parameter $\mu$ was significantly smaller for the intensive farms 


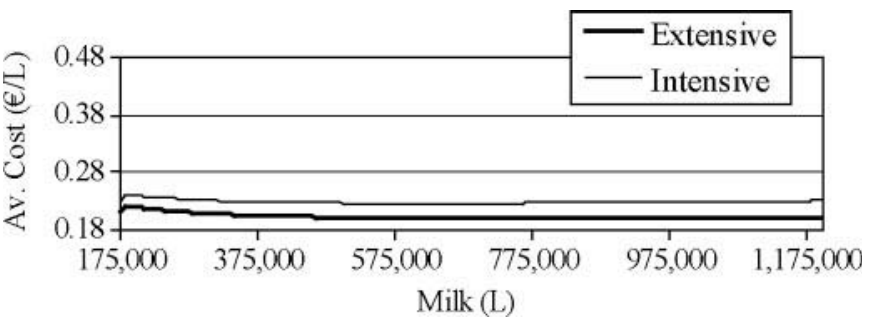

Figure 1. Frontier cost curve graphed from the regression shown in Table 4 and data for the 2006 agricultural year.

than for the extensive ones. Because $\mu$ (a parameter that characterizes the distribution of the inefficiency term $u$ ) reflects the inefficiency of the group of farms, we could conclude that intensive farms were less inefficient than the extensive ones. In other words, they were closer to their cost frontier.

To better describe the impact of intensification on production costs and farm efficiency, Figure 1 depicts the cost frontiers for the year 2006 by using the estimates presented in Table 4 and the average prices from each group. The difference between the 2 curves reflects disparities across the groups in terms of both technology and prices. As one can see, the frontier for the intensive group was always above the frontier for the extensive group. Because, by definition, farms on the cost frontier must be efficient, Figure 1 indicates that, at any production level, an efficient extensive farm could produce at a lower average cost than an efficient intensive farm. The minimum average total costs were 0.176 and $0.200 € / L$ for the extensive and intensive groups, respectively. These optima were achieved at 884,415 L (extensive) and 612,063 L (intensive). However, as shown in Table 3, the mean of the average total cost of all the intensive farms was lower than the mean of all extensive farms in this sample. Consequently, the findings of Figure 1 and Table 3 combined suggest that the greater level of average cost found for the extensive farms could be explained by the presence of inefficiencies. In the rest of this section, we explore this hypothesis.

Table 5 contains the descriptive statistics for the estimated levels of cost efficiency. The results show that the intensive group was more efficient with respect to its frontier than the extensive group was to its frontier. These results agree with the findings reported by Reinhard et al. (1999), who suggested that when dairy farms engage in more intensive production systems, they become more efficient. It is important to indicate that this difference was statistically significant based on a $t$-test $(t$-statistic $=22.77)$. Furthermore, the coefficient of variation was lower for intensive farms, showing that their efficiency levels were less dispersed.
Table 5. Cost efficiency descriptive statistics

\begin{tabular}{lcccc}
\hline Group & Mean & CV $^{1}$ & Minimum & Maximum \\
\hline Extensive & 0.72 & 0.11 & 0.56 & 0.93 \\
Intensive & 0.81 & 0.08 & 0.68 & 0.95 \\
\hline
\end{tabular}

${ }^{1} \mathrm{CV}=$ coefficient of variation.

Although our analysis did not explicitly explain why farms in the intensive system were more efficient than the extensive ones, we venture the possibility that the intensive system presented fewer technical challenges than the extensive one. More precisely, extensive farms use pastures to feed the cows; consequently, they perform several production activities on the farm (e.g., planting, fertilization, harvest, pasture silage, etc.) in addition to those performed by intensive farms, which base feeding mainly on purchased concentrates. These additional production activities increase the probability of making technical mistakes within the farm plan, which may negatively affect the level of efficiency among extensive dairy farms.

Finally, we explored the relationship between intensification and the economic results of the farms. Specifically, the net margin per liter (product value minus total production costs) was significantly greater for the intensive system $(0.05 € / L)$ than for the extensive system $(0.01 € / L)$.

\section{CONCLUSIONS}

Economically analyzing and comparing farms that use alternative levels of intensification in production is important to assess how intensification affects the final outcome of dairy farms. Our results show that intensive farms produced at a lower average total cost and presented greater levels of efficiency than extensive farms. In addition, the variance of the efficiency index was larger in the extensive group, suggesting the idea that farms under intensive production systems were easier to manage.

However, it must be stressed that our results cannot be interpreted per se as unconditional support for high-input systems. In fact, we also found that extensive farms, if managed efficiently, could compete with intensive farms because they produced at a lower cost. This result agrees with Tauer (2001), who suggested that efficient small farms could be cost competitive but, on average, they tended to be less efficient than large farms. On the other hand, cost efficiency depends critically on input prices. In this regard, the recent rise in the price of concentrates because of the increase in the price of cereals may diminish the cost differences between intensive and extensive farms. 
Our paper aimed to contribute to the debate on the advantages and disadvantages of intensive systems. The results of our analysis provide valuable information on the effects of intensification on farm efficiency. This issue has become very important because experts in this area predict that recent reforms of the European Union Common Agricultural Policy may cause a reduction in milk prices paid to farmers in Europe (Hennessy et al., 2005). In such an environment, improving farm efficiency is essential for the survival of dairy farms.

\section{ACKNOWLEDGMENTS}

The authors gratefully acknowledge the helpful comments received from 2 anonymous referees and the section editor, and the financial support provided by FICYT (grant PC06-28, Asturias, Spain) and ALFANERUDA (European Union). J. del Corral acknowledges the Spanish Ministry of Education and Culture for his Formación Profesorado Universitario (FPU) fellowship. D. Solís is thankful for the financial support provided by the Southeast Climate Consortium (US).

\section{REFERENCES}

Aigner, D., K. Lovell, and P. Schmidt. 1977. Formulation and estimation of stochastic frontier production function models. J. Econ. 6:21-37.

Aldenderfer, M., and R. Blashfield. 1984. Cluster Analysis. Sage, New York, NY.

Bravo-Ureta, B. 1986. Technical efficiency measures for dairy farms based on a probabilistic frontier function model. Can. J. Agric. Econ. 34:399-415.

Caviglia-Harris, J. L. 2005. Cattle accumulation and land use intensification by households in the Brazilian Amazon. Agric. Resour. Econ. Rev. 34:145-162.

Christensen, L., D. Jorgenson, and L. Lau. 1973. Trascendental logarithmic production frontiers. Rev. Econ. Stat. 55:28-45.

Everitt, B., S. Landau, and M. Leese. 2001. Cluster Analysis. 4th ed. Hodder Arnold Publisher, London, UK.
Hallam, D., and F. Machado. 1996. Efficiency analysis with panel data: A study of Portuguese dairy farms. Eur. Rev. Agric. Econ. 23:79-93.

Hennessy, T., L. Shalloo, and P. Dillon. 2005. The economic implications of complying with a limit on organic nitrogen in a decoupled policy environment-An Irish case. J. Farm Manage. 12:297-311.

Hoch, I. 1962. Estimation of production function parameters combining time-series and cross-section data. Econometrica 30:34-53.

Katsumata, K., and L. W. Tauer. 2005. An empirical analysis of stanchion and parlor milking cost in New York dairy farms: Cost curve and cost function approaches. Dept. Applied Econ. Manage., Cornell Univ., Ithaca, NY.

Kumbhakar, S., and K. Lovell. 2000. Stochastic Frontier Analysis. Cambridge Univ. Press, Cambridge, UK.

Ledgard, S. F., J. D. Finlayson, M. S. Sprosen, D. M. Wheeler, and N. A. Jollands. 2004. Effects of intensification of dairy farming in New Zealand on whole-system resource use efficiency and environmental emissions. Pages 226-260. In Life Cycle Assessment in the Agri-food Sector. N. Halberg, ed. Dan. Instit. Agric. Sci., Tjele, Demark.

Newman, C., and A. Matthews. 2006. The productivity performance of Irish dairy farms 1984-2000: A multiple output distance function approach. J. Prod. Anal. 26:191-205.

Parker, W. J., L. D. Muller, and D. R. Buckmaster. 1992. Management and economic implications of intensive grazing on dairy farms in northeastern states. J. Dairy Sci. 75:2587-2597.

Pérez, J. A., and A. Machado. 2001. Evolución económica y análisis de resultados en una muestra de explotaciones lecheras del Occidente de Asturias (1993-1998). Econ. Agrar. Recursos Nat. 1:43-46.

Reinhard, S., K. Lovell, and G. Thijssen. 1999. Econometric estimation of technical and environmental efficiency: An application to Dutch dairy farms. Am. J. Agric. Econ. 81:44-60.

Simpson, J. R., and J. H. Conrad. 1993. Intensification of cattle production systems in Central America: Why and when. J. Dairy Sci. $76: 1744-1752$.

Soder, K. J., and C. A. Rotz. 2001. Economic and environmental impact of four levels of concentrate supplementation in grazing dairy herds. J. Dairy Sci. 84:2560-2572.

Tauer, L. W. 1998. Cost of production for stanchion versus parlor milking in New York. J. Dairy Sci. 81:567-569.

Tauer, L. W. 2001. Efficiency and competitiveness of the small New York dairy farm. J. Dairy Sci. 84:2573-2576. 